\title{
ASSOCIAÇÃO ENTRE A MICROBIOTA INTESTINAL E A DOENÇA DE PARKINSON
}

\section{ASSOCIATION BETWEEN INTESTINAL MICROBIOTA AND PARKINSON'S DISEASE}

\author{
Camily Ingrid Araújo Silva ${ }^{1}$ \\ Cristiane Barreto Andrade Ferreira ${ }^{2}$ \\ Julieta Mendes Medeiros Facundes ${ }^{3}$ \\ Laryssa Cristhina Cassimiro Evangelista ${ }^{4}$ \\ Letícia Cristina Araújo Lima \\ Maria Cristina Martins Moraes ${ }^{6}$ \\ Silvia Mara Martins ${ }^{7}$ \\ Luiz Fernando Alves dos Reis ${ }^{8}$
}

RESUMO: A Microbiota Intestinal (MI) é caracterizada pela presença de microrganismos que habitam dentro do trato gastrointestinal, contendo vírus, fungos, bactérias e protozoários. A disbiose da MI é um fator que contribui para o desenvolvimento da doença de Parkinson (DP) devido a ligação do eixo cérebro-intestino-microbiota, através do nervo vago. A doença de Parkinson é caracterizada por distúrbios neurológicos, degenerativo e progressivo. Uma vez que inibe a capacidade de sintetizar neurotransmissores levando ao aparecimento dos corpos de Lewy, cuja composição é formada pela proteína alfa-sinucleína em sua forma tóxica. Conforme seu avanço ela se torna cada vez mais incapacitante, comprometendo a realização de atividades diárias. Sendo necessário recorrer a medidas preventivas, em função da recomposição da MI e prevenção da disbiose. Através da utilização de prebióticos e probióticos.

Palavras-Chaves: Microbiota Intestinal. Disbiose. Alfa-sinucleína. Doença de Parkinson.

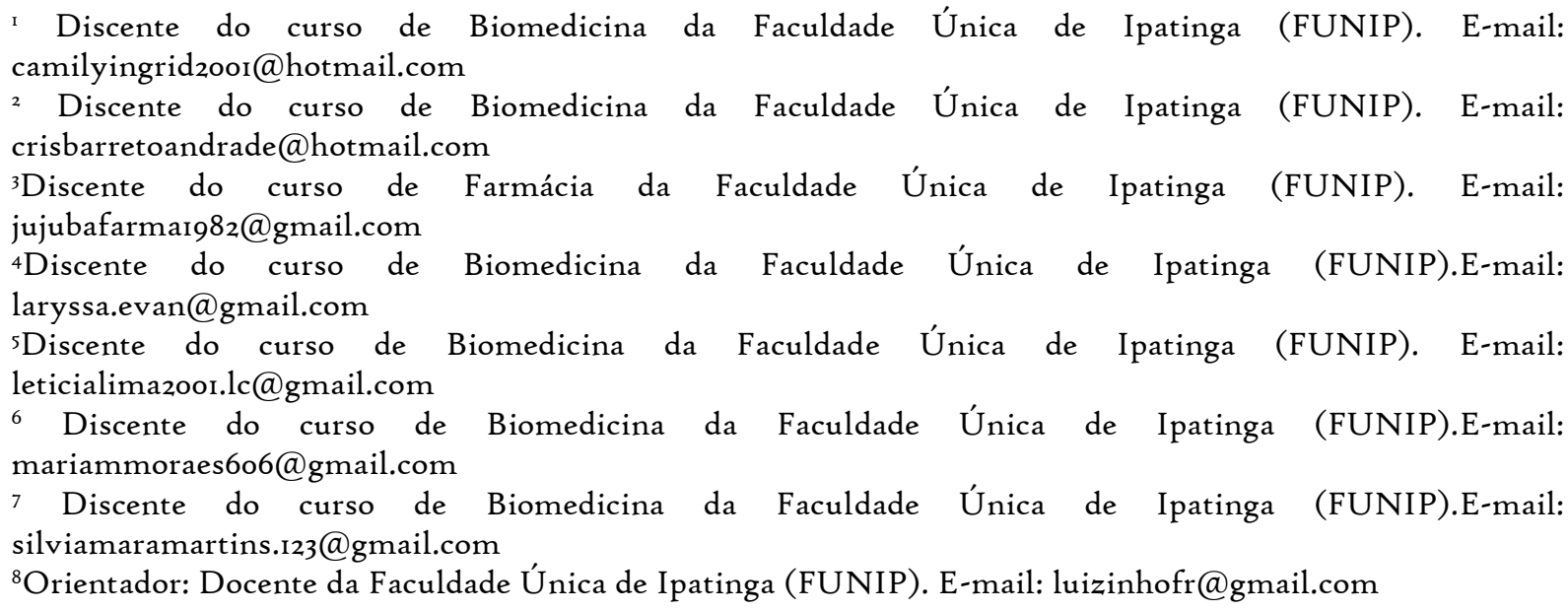


ABSTRACT: The Intestinal Microbiota (IM) is characterized by the presence of microorganisms that inhabit the gastrointestinal tract, containing viruses, fungi, bacteria and protozoa. IM dysbiosis is a factor that contributes to the development of Parkinson's disease (PD) due to the connection of the brain-gut-microbiota axis, through the vagus nerve. Parkinson's disease is characterized by neurological disorders, degenerative and progressive. Since it inhibits the ability to synthesize neurotransmitters leading to the appearance of Lewy bodies, whose composition is formed by the alpha-synuclein protein in its toxic form. As you progress, it becomes more and more disabling, compromising the performance of daily activities. It is necessary to resort to preventive measures, due to the recomposition of IM and prevention of dysbiosis. Through the use of prebiotics and probiotics.

Keywords: Intestinal Microbiota. Dysbiosis. Alpha-synuclein. Parkinson's disease.

\section{INTRODUÇÃO}

A Microbiota Intestinal (MI) é caracterizada por sua diversidade de microrganismos, como vírus, fungos, bactérias e protozoários presentes no intestino. Exercendo um papel importante na homeostase e no sistema digestório. O desequilíbrio desses microrganismos (disbiose) é responsável pelo aparecimento de alterações no processo digestivo, contribuindo para o desenvolvimento de processos inflamatórios, encontrados em patologias como a doença de Parkinson (NEUHANNIG, et al. 2019).

A doença de Parkinson (DP) é uma doença neurodegenerativa que acarreta danos ao Sistema Nervoso Central (SNC) e é definida pela diminuição dos neurotransmissores dopaminérgicos. As manifestações clínicas desta doença são tremores, fadiga, instabilidade, perda dos movimentos automáticos e alterações gastrointestinais (DA MOTA GANTUSS, et al. 2021).

Interferindo assim, de maneira direta na qualidade de vida do paciente diagnosticado (NAVARRO-PETERNELLA, 2012). Dados epidemiológicos, mostram que os casos desta doença tendem a crescer cada vez mais. Diante disso, a profilaxia com a utilização de prebióticos e probióticos é de extrema importância (FERNANDES, 2018).

Os probióticos agem diretamente na alteração da disbiose, reduzindo o fluxo de passagem bacteriana e a neuroinflamação (PEREZ-PARDO, et al. 2017). Enquanto os prebióticos estão relacionados à necessidade de estimular o aumento das bactérias produtoras de butirato (KESHAVARZIAN, et al. 2015; UNGER, et al. 2016). 
A associação da DP e a MI ocorre por meio da proteína alfa-sinucleína presente na maioria dos neurônios, quando ligadas em excesso aos corpos de Lewy tem-se um fator de predisposição a DP. Em condições patológicas, essa proteína compõe os corpos de Lewy de maneira tóxica e insolúvel. Desta forma, pode-se afirmar que a doença tem início no intestino, alcançando o SNC causando um quadro de neuroinflamação devido ao excesso da proteína alfa-sinucleína no Sistema Nervoso Entérico (SNE) (DA SILVA, 202I).

O objetivo do presente estudo foi abordar a associação da microbiota intestinal e a doença de Parkinson. Apresentando estratégias de prevenção à neuroinflamação.

\section{METODOLOGIA}

Este estudo trata-se de uma revisão de literatura sobre a associação da microbiota intestinal e a doença de Parkinson. Para tanto, buscou-se artigos científicos publicados em revistas indexadas hospedadas em Bases de Dados da Biblioteca Virtual em Saúde (BVS Bireme) com o uso mais frequente da Scielo (ScientificElectronic Library OnLine) e também o Google Acadêmico.

Os artigos científicos selecionados atenderam os critérios de inclusão estabelecidos pelos autores da pesquisa: relevância do tema, artigos de revisão, data de publicação de 2005 até 2021, no idioma português e inglês. $\mathrm{O}$ intervalo entre as datas de publicação (2005 a 202I) foi devido à relevância de artigos que enfatizavam a associação da microbiota intestinal e a doença de Parkinson.

Os artigos foram selecionados em grupos: primeiro grupo de artigos foram aqueles que traziam, em seu texto, apenas assuntos relacionados à microbiota intestinal; o segundo grupo de artigos traziam, em seu texto, apenas assuntos relacionados à doença de Parkinson e o terceiro grupo de artigos traziam, em seu texto, a associação entre os dois assuntos: microbiota intestinal e Parkinson.

Os artigos classificados nos grupos i e 2 foram utilizados como referencial teórico deste trabalho. 


\section{DESENVOLVIMENTO}

\section{I Microbiota intestinal}

A Microbiota Intestinal (MI) constitui-se da agregação de microrganismos presentes no intestino humano. Formada por vírus, fungos, bactérias e protozoários, tem como função a execução de funções vitais para com a manutenção da homeostase. Através da comunicação bidirecional intestino-cérebro, exercendo um papel modulador no eixo cérebro-intestino-microbiota. Evidencia-se sua influência no desenvolvimento e funções cerebrais, isso devido a sua inter-relação com as vias neurais, endócrinas e imunitárias (LANDEIRO, 2016).

A dieta é o principal fator responsável pelo equilíbrio da microbiota, refletindo em sua interação com o hospedeiro. No entanto, o desequilíbrio destas diversidades de microrganismos (disbiose) auxilia no aparecimento de alterações desde o processo digestivo, a reabsorção de nutrientes dos alimentos até o controle dos inúmeros agentes patológicos. Visto que tais agentes, tem a capacidade de atravessar a barreira do epitélio intestinal e como consequência a barreira hematoencefálica (BHE) (SACRAMENTO, 2020)

Portanto, a MI pode influenciar de maneira direta o SNC devido a sua capacidade de sintetizar neurotransmissores. Assumindo um papel extremamente importante na fisiopatologia, desenvolvimento e na progressão de doenças neurodegenerativas, com ênfase na doença de Parkinson (NESI, 202I).

\subsection{Doença de Parkinson}

A doença de Parkinson é habitualmente encontrada em idosos, associada ao processo de envelhecimento. Incurável e caracterizada pela deterioração progressiva dos neurônios dopaminérgicos localizados na substância negra do encéfalo. Uma vez que a dopamina é um neurotransmissor responsável pelo controle dos movimentos (FARIA, et al. 2019). A destruição destes neurônios está relativamente voltada a agregação dos mesmos junto a proteína alfa-sinucleína (YANG, et al. 2019). 
A figura I apresenta as alterações nos neurônios dopaminérgicos na doença de Parkinson, comparado a condições normais. Enfatizando o processo de deterioração deste neurotransmissor.

Figura I: Alteração nos neurônios dopaminérgicos na doença de Parkinson

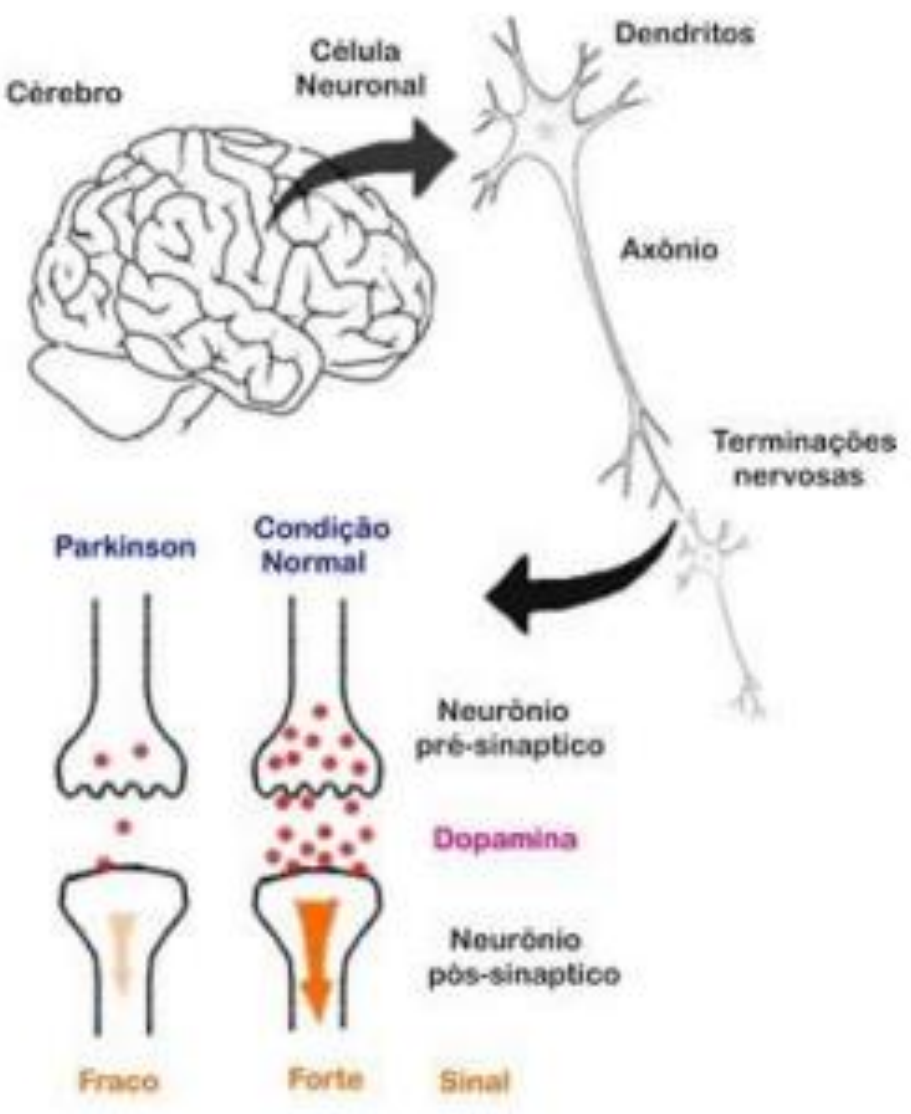

Fonte: PIRES, 2020

Manifesta-se clinicamente através da mácula de atividades diárias, devido a presença de movimentos anormais. Apresentando sintomas motores como tremores, rigidez, instabilidade, perda de movimentos automáticos e não motores como alterações gastrointestinais, cardiovasculares, urogenitais (PIRES, 2020).

Acometendo a qualidade de vida dos pacientes, uma vez que há um comprometimento de habilidades físicas, atividades diárias e a autoestima dos mesmos (NAVARRO-PETERNELLA, 2012). 
De acordo com dados epidemiológicos, em 2005 mais de 4 milhões de indivíduos com idade acima de 50 anos enfrentavam a doença. É estipulado que até o ano de 2030, o número de diagnosticados dupliquem (FERNANDES, 2018).

\subsection{Associação da microbiota intestinal com a doença de Parkinson}

A comunicação intestino-cérebro se dá através do nervo vago. Trata-se do nervo mais extenso encontrado no corpo humano onde seu início se dá atrás do bulbo raquidiano, passando pelo pescoço e indo até o estomago, dando origem a muitas outras ramificações nervosas. Dentre elas encontra-se a ramificação intestinal, enviando mutualmente sinais do trato gastrointestinal ao encéfalo (MONDAL, et al. 202I). Suas formas de sinalização acontecem por meio de substâncias presentes na MI, dentre elas estão os lipopolissacarídeos e os estimulantes imunológicos (FARZI, 20I8).

A associação Microbiota Intestinal e Doença de Parkinson, está diretamente ligada a presença mútua da proteína alfa-sinucleína, sendo uma proteína importante por estar indexada aos corpos de Lewy nos neurônios em deterioração. Presente em grande parte dos neurônios, cuja localização se dá na fase terminal dos neurônios pré-sinápticos. Os corpos de Lewy tem em sua composição a proteína alfa-sinucleína de maneira tóxica e insolúvel, fator de predisposição à DP (DA SILVA, 2021).

A disbiose é caracterizada pelo aumento de microrganismos patogênicos no trato gastrointestinal. Este desequilíbrio ocasiona um quadro inflamatório, que aumenta a permeabilidade do epitélio intestinal, possibilitando a entrada dos patógenos na corrente sanguínea (SILVA, 2017). Com isso a MI é induzida a produzir a proteína alfa-sinucleína. Esta proteína em forma de uma molécula infecciosa se propaga pelo nervo vago, acometendo inicialmente o Sistema Nervoso Entérico (SNE), ocasionando o desenvolvimento de sintomas motores presentes na doença de Parkinson. Após este acometimento a proteína se espalha para o restante do cérebro através das fibras do nervo vago (QUEIROZ, 2017).

Os chamados Corpos de Lewy são neurofilamentos, de localização intracitoplasmática, esféricas e eosinofílicas, podendo também apresentar formas ovoides e alongadas. Podem ser classificados como Corpos de Lewy clássicos, que apresentam 
estruturas com o centro hialino circundado por halo claro, encontrados normalmente em neurônios da substância negra (Doença de Parkinson) e os Corpos de Lewy corticais que se tratam de estruturas menos definidas, possuem halo claro e se localizam em neurônios corticais (AZZI-NOGUEIRA, 2016).

Por meio dos critérios citados a doença em questão apresenta alterações gastrointestinais antes mesmo do aparecimento de sintomas motores. $\mathrm{O}$ acumulo da proteína alfa-sinucleína no Sistema Nervoso Entérico (SNE), faz com que chegue ao Sistema Nervoso Central (SNC), acarretando uma neuroinflamação. Sendo assim, podese afirmar que a doença tem seu início no intestino, alcançando posteriormente o SNC através do nervo vago (TOMÉ, 2013).

\subsection{Profilaxia}

É de suma importância o desenvolvimento de estratégias preventivas relacionadas a doença de Parkinson, uma vez que essa doença não tem cura e afeta diretamente à qualidade de vida dos pacientes. Tais medidas tem como principal finalidade, modificar a composição da MI, para que não ocorra a disbiose. Interrompendo a neurodegeneração causada pela doença (CRYAN, 2012).

A utilização de probióticos e prebióticos tem grande eficácia. Os probióticos são composições de bactérias e leveduras vivas, sendo os mais utilizados Lactobacilli, Enterococci e Bifidobacteria. Mantendo intacto o epitélio intestinal, com o objetivo de aumentar a imunidade, diminuindo o crescimento de bactérias patogênicas e impedindo que a barreira do intestino se rompa (SARTOR, 2005; PATEL, et al. 2012).

$\mathrm{Na}$ prevenção contra a DP, os probióticos são eficazes na alteração da disbiose. Reduzindo o escape intestinal, a passagem bacteriana e a neuroinflamação, relacionada ao Sistema Nervoso Entérico (PEREZ-PARDO, et al. 2017).

Os prebióticos são oligossacarídeos, sendo os mais comuns galacto-oligossacarídeos (GOS) e os fruto-oligossacarídeos (FOS), que acidificam o cólon impossibilitando o crescimento de bactérias patogênicas (KOVÁCS, et al. 2013). As fibras prebióticas melhoram a imunidade, a motilidade do intestino e o crescimento de bactérias produtoras de butirato (MEKSAWAN, et al. 2016). 
Sua relação com a DP se dá devido ao fato de os pacientes diagnosticados com a doença possuírem pouca abundância das bactérias produtoras de butirato. Essa deficiência pode ser corrigida com o uso das fibras prebióticas (KESHAVARZIAN, et al. 2015; UNGER, et al. 2016).

\section{CONSIDERAÇÕES FINAIS}

A Microbiota Intestinal possui relação com a doença de Parkinson, uma vez que a disbiose é o fator inicial para que ocorra a DP. Tendo como consequência o comprometimento das habilidades físicas e diárias. Diante disso, é notório a importância de uma conduta estratégica para sua prevenção, por meio da utilização de prebióticos e probióticos. Uma vez que a ingestão deles tem a função de recompor a MI, prevenindo o surgimento da DP.

Embora a MI seja de conhecimento geral, recomenda-se uma atenção voltada a sua regulação, como uma estratégia de prevenção ao surgimento da DP. Para tanto a realização de estudos mais aprofundados sobre o assunto e uma maior divulgação é de suma importância. Afim de que todos tenham ciência de sua importância.

\section{REFERÊNCIAS BIBLIOGRÁFICAS}

AZZI-NOGUEIRA, Deborah. Os produtos dos genes Tsci e Tsc2 em processos neurodegenerativos. Tese de Doutorado. Universidade de São Paulo.

CRYAN, John F.; DINAN, Timothy G. Microrganismos que alteram a mente: o impacto da microbiota intestinal no cérebro e no comportamento. Nature reviews neurcience , v. I3, n. Io, pág. 701-712, 2012.

DA MOTA GANTUSS, Ana Sandrina et al. Efeitos da realidade virtual na qualidade de vida em parkinsonianos. Revista Neurociências, v. 29, p. I-I8, 2021. 
DA SILVA, Caroline Felix; AZEVEDO, Graziele Estevo; TAKETANI, Natália Franco. MICROBIOTA INTESTINAL RELACIONADA A DOENÇA DE PARKINSON. Revista Ensaios Pioneiros, v. 5, n. I, pág. 49-6o, 2021.

FARIA, Stephanie Martins de et al. Impacto dos sintomas de ansiedade na qualidade de vida na doença de Parkinson: uma revisão sistemática. Jornal Brasileiro de Psiquiatria, v. 68, p. 48-55, 2019.

FARZI, Aitak; FRÖHLICH, Esther E.; HOLZER, Peter. Microbiota intestinal e o sistema neuroendócrino. Neurotherapeutics, v. 15, n. I, pág. 22/05/2018.

FERNANDES, Itana; DE SOUZA ANDRADE FILHO, Antônio. Estudo clínicoepidemiológico de pacientes com doença de Parkinson em Salvador-Bahia. Revista Brasileira de Neurologia e Psiquiatria, v. 22, n. I, 2018.

KESHAVARZIAN, Ali et al. Composição bacteriana do cólon na doença de Parkinson. Distúrbios do Movimento, v. 30, n. I0, pág. 1351-1360, 2015.

KOVÁCS, Zoltán et al. Desenvolvimentos recentes na fabricação de oligossacarídeos com funções prebióticas. Biotecnologia de alimentos e aditivos para rações, p. 257-295, 2013.

LANDEIRO, Joana Almeida Vilão Raposo. Impacto da microbiota intestinal na saúde mental. 20I6. Tese de Doutorado.

MEKSAWAN, Kulwara et al. Efeitos da suplementação de fruto-oligossacarídeo na constipação em pacientes idosos em diálise peritoneal ambulatorial contínua. Peritoneal Dialysis International , v. 36, n. I, pág. 6o-66, 2016. 
MONDAL, Banashree et al. A estimulação do nervo vago não invasiva melhora os biomarcadores clínicos e moleculares da doença de Parkinson em pacientes com congelamento da marcha. npj Parkinson's Disease, v. 7, n. I, pág. I-II, 202I

NAVARRO-PETERNELlA, Fabiana Magalhães; MARCON, Sonia Silva. Qualidade de vida de obrigação com Parkinson e sua relação com o tempo de evolução e gravidade da doença. Revista Latino-Americana de Enfermagem, v. 20, p. 384-391, 2012.

NEUHANNIG, Camila et al. Disbiose Intestinal: Correlação com doenças crônicas da atualidade e intervenção nutricional. Research, Society and Development, v. 8, n. 6, p. e25861054-e25861054, 2019.

NESI, Gabriela Antoniolli; FRANCO, Mariana Ramos. A disbiose da microbiota intestinal, sua associação no desenvolvimento de doenças neurodegenerativas e seus possíveis tratamentos. 2021.

PEREZ-PARDO, Paula et al. O eixo intestino-cérebro na doença de Parkinson: possibilidades para terapias baseadas em alimentos. Jornal Europeu de Farmacologia, v. 817, p. 86-95, 2017.

PATEL, Ravi M. et al. As bactérias probióticas induzem a maturação da expressão da claudina 3 intestinal e da função de barreira. The American Journal of Pathology , v. I8o, n. 2, pág. 626-635, 2012.

PIRES, Inês Maria Antunes. Relação entre a doença de Parkinson e as doenças inflamatórias gastrointestinais. Tese de Doutorado.

QUEIROZ, João Pedro Nunes. O microbiota e o ser humano. 2017. Tese de Doutorado. Universidade de Coimbra. 
SACRAMENTO, Maria João de Sousa. Relatórios de Estágio e Monografia intitulada “A Influência da Microbiota Intestinal nas Doenças Neurodegenerativas”. 2020. Tese de Doutorado. Universidade de Coimbra.

SARTOR, R. Balfour. Terapia probiótica de inflamações e infecções intestinais. Opinião atual em gastroenterologia, v. 2I, n. I, pág. 44-50, 2005.

SILVA, Miguel Pereira da. Relatórios de Estágio e Monografia intitulada "O Parkinson, a Microbiota Intestinal e a Epigenética". 2017. Tese de Doutorado. Universidade de Coimbra.

TOMÉ, Carla M. Lema et al. Inflamação e comportamento semelhante ao prião da $\alpha$ sinucleína na doença de Parkinson - existe uma ligação?. Neurobiologia molecular, v. 47, n. 2, pág. 56I-574, 2013.

UNGER, Marcus M. et al. Os ácidos graxos de cadeia curta e a microbiota intestinal diferem entre pacientes com doença de Parkinson e controles pareados por idade. Parkinsonismo e doenças relacionadas, v. 32, p. 66-72, 2016.

YANG, Dongming et al. O papel da microbiota intestinal na patogênese da doença de Parkinson. Fronteiras em neurologia, v. Io, p. II55, 2019. 